\title{
DISCOURSE ANALYSIS (DA) IN TRANSLATOR TRAINING
}

\section{Gülfidan Ayvaz *}

*Sakarya University E-mail: gayvaz@sakarya.edu.tr

Copyright (C) 2015 Gülfidan Ayvaz. This is an open access article distributed under the Eurasian Academy of Sciences License, which permits unrestricted use, distribution, and reproduction in any medium, provided the original work is properly cited.

\begin{abstract}
Translator training enables students to gain experience in both linguistic parameters and translation practice. Discourse Analysis is one of the strategies that lead to a better translation process and quality in translation. In that regard, this study aims to present DA as a translation strategy for translation practice and a useful tool for translator training. The relationship between DA and Translator Training is not widely studied. Therefore this study aims to define DA and how it can be used in translation practice and Translator Training.
\end{abstract}

Keywords: Discourse, translation, discourse analysis, translator training, translation trainee

\section{Çevirmen Eğitiminde Söylem Analizi}

\section{ÖZET}

Çevirmen eğitimi, öğrencilerin hem dilbilimsel parametrelerde hem de çeviri pratiğinde deneyim kazanmasına olanak sağlar. Söylem analizi, daha iyi bir çeviri sürecine ve çeviride kaliteye yönelten stratejilerden biridir. Bu bağlamda, bu çalışma, söylem analizini çeviri pratiğinde kullanılabilecek bir çeviri stratejisi ve çeviri için yararlı bir araç olarak sunmayı hedeflemektedir. Söylem analizi ve çevirmen eğitimi arasındaki ilişki geniş kapsamlı olarak araştırılmamıştır. Bundan dolayı, bu çalışma söylem analizini tanımlamayı ve onun çeviri pratiği ve çeviri eğitiminde nasıl kullanılabileceğini gösterme amacı taşımaktadır.

Anahtar Kelimeler: Söylem, çeviri, söylem analizi, çevirmen eğitimi, çeviri öğrencisi

\section{Introduction}

This study is an examination of the relationship between Discourse Analysis and Translator Training. DA is significant method in analyzing both the source text and target requirements therefore a helpful translation strategy both for professionals and translation trainees. Before going into details of the relationship of these interdisciplinary fields, we should define what discourse analysis is.

The ways in which we understand and represent the world are historically and culturally specific and contingent; our worldviews and our identities could have been different, and they can change over time. Discourse is a form of social action that plays a part in producing the social world-including knowledge, identities and social relations-thereby in maintaining 
specific social patterns (Jørgensen, Phillips, 2002: 5). It means that discourse is an explanandum including our all social and cultural patterns.

Discourses represent culture-specific elements of a certain group or society which are reflected in language use. Therefore, discourse analysis can be used to shed light translation practice and strategies. It would be challenging for a translator to analyze the characteristics of a source text or a speech without DA, as they will have trouble understanding the culture, ideology and reflections of the source language and culture. Such a misunderstanding yields to incoherence of the target text and DA can minimize this incoherence.

In that context, our study deals with the DA as a translation strategy and a useful instrument in translator training. We will investigate the interaction of DA and translator training from different aspects.

\section{Discourse and Discourse Analysis}

Discourse can be called as utterances belonging to individual and community in which it is formed social, cultural and geographic conditions. These utterances provide information about receiver and sender who have lived in certain periods. Discourses which tell us the soul of a certain period combining with the individual psychology have also effective, informative and operative characteristics.

Literary texts can be given as the apparent examples of the reflection of discourse. Novels, poetry, theatre and other literary works indicate the social, psychological, cultural and periodical features of a certain society and literary movement.

If it is maintained for this purpose, it can be said that the informative discourses are uttered in order to give information to another receiver. They can be analyzed in advertisement texts, brochures, prescriptions, instruction books, news etc. Additionally, the operative discourses can be seen in protests, political decisions or conversations, public speeches etc. The discourses in these practices are produced to create an impact on the human's sense. From this point of view, discourses change in terms of their aim and target market/group. Here, the method which investigates the discourses analyzing their production phase, purpose of the production and target culture is Discourse Analysis (DA).

According to Sayfuldeen, "discourse analysis is looked upon as involving both language form and language function and including that part of communication that is unfolded in spoken or written texts by means of various linguistic devices" (Sayfuldeen, 2010: 28). Linguistic devices mentioned here are; semantic, pragmatic and syntactic components that take place in the background of discourses. Taking such components into account discourse is analyzed and such an analysis grounds the base for a quality translation.

\section{Discourse and Translation}

Even though discourse and translation seem to be different, they are bound with each other. While the translation investigates discourse in source text and tries to transfer this discourse into target text, discourse varies according to genre and function of source text and also characteristics of receivers. Discourses in both written and spoken texts appear at the center of translation act. Hence, translation must be not fulfilled without discourse analysis.

According to van Dijk (1997, 2001), ideology is articulated in discourse. Therefore, translation can also articulate, that is produce and reproduce, ideology (Mahdiyan, Rahbar, Hosseini-Maasoum, 2013: 40). Apart from ideology, cultural senses, rhetoric utterances, lifestyles of community or individual, psychological tendencies and socio-cultural norms are articulated in discourse. In this sense, translation ensures proximity between the communities as discourses involve this multi-oriented meaning. While transferring this multi-oriented meaning, translator is aware that he/she is not only responsible for transferring the meaning 
but also finding equivalences of social features of ST in the TT. Translating is a sort of cultural familiarizing in that regard.

Especially, in the case that translation is regarded as discourse practice, translator is not only a text producer, also a discourse analyst. In order to find the best utterance for target text translator must solve the correlation between source and target receivers. Because of this, he needs to a Discourse Analysis (DA). With this method, discourses in original and translated texTP can be analyzed by linguistic devices. Discourse Analysis provides the translator and receiver a better understanding, interpretation and also to develop empathy towards the source receivers.

The mixture of DA into TP (translation practices) enabled to deal with concept of translation from a different angle. While the source text is produced in some specific socio-cultural situation in accordance with the norms and values of that society or organization, the translator's socio-cultural background, linguistic background and experience with other texts and discourses directly affect the final product of the act of translation in target text (Mahdiyan, Rahbar, Hosseini-Maasoum, 2013: 36-37). Thus, discourses which are arranged in accordance with the norms of target language are used in the phase of text production. In this phase, a lot of factors play a part. These factors take place in discourse analysis too. For further conclusions it must be looked into discourse analysis through translation.

\section{Discourse Analysis through Translation}

Discourse Analysis through Translation (DAtT) is a process which brings translators many responsibilities both in the context of source text and target text. In this process translator approaches to source text as a discourse analyst who carries out discourses in their all linguistic units and as a text producer who can compare the discourses in source text with in target text and get an equivalence between both texts. Analyzing the linguistic units yield to not only semantic, pragmatic and syntactic research but also the investigation of cultural, communicational, lingual, sociological, individualistic and periodical elements within source and target text.

Hence, it is possible to state two main purposes in the translation: a) the translator must convey information with certain changes in the TT (According to Valdéon (2007: 102) omissions, additions, permutations and substitutions may be included in the vocabulary of DA as well, since they are connected to the editing and production processes of STP and TTP) (Dynamic approach). b) the translator conveys information in the TT with no significant changes according to word for-word translation strategy (static approach) (Mahdiyan, Rahbar, Hosseini-Maasoum, 2013: 38). Which path translator will choose depends on the text-type and its function. Therefore it is significant which strategy translator will choose during translation practice. Is the aim to introduce the culture of source text or influence the target receiver? With such an aim in mind, translator analyses discourse and writes the target text. In terms of text genre translator decides that the discourses are effective, informative and operative. Nearby, it should be not forgotten the ground of language in context. Because an utterance can imply another meanings out of written or spoken, the meaning of discourses changes in accordance with the place in which are used in texts. The notion of context is worthy of notice. The effect of context in enabling the cohesion is not to be underestimated. If we examine the interwoven relationship of text and context, we notice the importance of context. Text is defined as "any passage, spoken or written, of any length that forms a unified form". Context is defined as "aspects of extra-linguistic reality that are taken to be relevant to the communication". Based on these two definitions, context, from one hand, shapes the text and, from the other hand, is shaped by the text (Farahani, 2013: 112). This relation between text and context looks like the relation between translation and discourse; translation needs 
discourses in order to transfer utterances from source to target text and discourses constitute translated text. Consequently, discourse in a certain context exists the translated text.

Translation act involves semantic and pragmatic discourse analysis. In other words, a semantic analysis can be conducted to examine the relationship between thought and the meaning, when the same process is done in target language we can speak of semantic translation. Hence, semantic and pragmatic translations are also mentioned. Semantic translation surveys the discourse structure of source and target text.

According to Sayfudeen, "semantic translation aims at conveying the semantic and syntactic structure of the (SL) text. In other words, it concentrates on the content of the message rather than the effect of the message. In semantic translation, the translator is very loyal to the author of the original text more than anything else. Then, semantic translation seems to be more complex, more concentrated and inclusive of more details. Anyway, semantic translation may result in loss of meaning and might lead to poorly written texts" (Sayfuldeen, 2010: 31). However, pragmatic translation concentrates on the effect of the message in spoken or written text. The aim is to affect the target reader the way the source text reader is affected.

For instance: "It never rains but it pours! First I found that the car had been stolen and then I lost the keys to my flat" (Oxford Idioms, 2001: 310). If we want to translate this sentence to German language, for a semantic translation it is correct "Es regnet nie, aber es schüttet! Zuerst fand ich dass das Auto gestohlen wurde und dann ich meinen Schlüssel meiner Wohnung verlor." With this translation we can convey the content of source sentence but not the context in sentence. To convey the context, the pragmatic analysis becomes inevitable. In that way we can transfer the effect of the source sentence into the target sentence. By pragmatic translation the sentence will be more meaningful and affective for receivers. This sentence can be translated "Ein Unglück kommt selten allein. Erstmalig fand ich dass das Auto gestohlen wurde und dann ich meinen Schlüssel meiner Wohnung verlor."

However, in order to be aware of the complexity involving the translation process, the translator needs to acquire the various levels of knowledge and abilities which constitute the translating process such as: reading, reflection, research, interpretation and writing - the latter being an essential skill for the translator's good performance (Olher, 2004: 74).

The skills for the translator's good performance can be put in order as following:

- Reading the source text regarding discourse patterns

- Discourse analysis of source culture

- Researching the discourses of target culture appropriate to source text

- Mutual interpretation of discourses in source and target culture

- Writing a target text that has similar effects of a source text

As it is already uttered, DAtT requires a translator to perform the above mentioned phases. Associated with the translation practices oriented target receiver, discourse analysis has begun to take place in translation practices. Thus, translator transfers not the information from source text in sense for sense way, on the contrary, in an illocutionary way. According to target audience, they make a decision which discourses have influence on target receiver.

Furthermore, Olher asserts for translation: "analyzing translation as a communicative activity where translators are readers, interpreters, writers and above all discourse analysts, we understand that translation is not a mere linguistic code receiving or sending activity related to exclusive lexicogrammatical aspects of language, but it is rather an identification of text genre, contextualization of facts and ideas, taking into account the author's original information and the target readers or receivers of the translated text (Olher, 2004: 76). Moreover, whether the translation has been in sight as the process of linguistic code transfer, 
the translated text neither in spoken nor written could be incomprehensible. D.A. is important as our all attempt is to understand the source text within the norms of target language. Understanding the discourses of target linguistic norms requires an analysis as well.

Olher voices in this sense that the translation activity should be studied as a discursive practice, where different reflexive actions are performed, such as: reading, interpreting, analysis, making decisions and others, which surpass the level of words and sentences reaching the level of discourse (Olher, 2004: 75). Apart from Olher's asserts, the meaning in the background of discourses is a fact that must be paid attention in the translation phase.

Let's say that a married couple is sitting around the dining table.

Woman: Eat is prepared but there is no bread.

Man: I go to the market.

The reason that the man goes to the market reveals to be understood the woman's discourse by the man. With the discourse "Eat is prepared but there is no bread" the woman utters that they need bread and the man should buy a bread. Here, translator must analyses both discourse of woman and man. Also, translator is able to reflect the effect of woman's discourse into target text.

In the abovementioned conversation the man acts on woman's discourse which indicates a pragmatic communication process. However, we should keep in mind that the couple has a common discourse. We examined this particular conversation as it indicates the sociological and psychological factors in determining the discourse. The man's and woman's social status demonstrate that they are married while psychological discourse stems from living together. The man goes to market to buy bread which suggests that he is aware of his responsibilities in marriage. Pragmatic is a constituent of discourse which signifies the close relationship of discourse and pragmatics. Pragmatics and discourse are parallel processes in translating. Therefore, the abovementioned conversation of the married couple indicates not only a pragmatic analysis but also a discourse analysis as well.

In the context of speech analysis, we have to underline another basic point, which is the importance of the beginning and the end of the text to be interpreted. The beginning is just like the starting point of a journey, and it often includes significant elements which are useful to understand the overall meaning of a speech (Sayfuldeen, 2010: 33). These points are related both woman and man's mutual knowledge of the situation. They have common opinions toward this situation, because they eat together. For this reason, man deduces from the woman's discourse that he should buy bread. The fact that speaker implies gets over from hearer shows they share a common lifestyle and common ground of their knowledge.

DA in TP is necessary for an analyzing of discourses in common ground. Translator must analyze widely the ideology, opinions, beliefs, lifestyles, culture, education levels, statutes of the author and source and target receiver. If translator finds a common ground between source and target text, a translated text can be written to gather translator's own textual knowledge and translation experiences. The place of the term "common ground" in translation requires multiple research. To this respect, it is mentioned shortly in line with the purpose of this study. Common ground mentioned here is different than the concept of common ground in pragmatics. The intention of the common ground in our study, is to construct a common discourse in target language taking into consideration both cultural and textual feature of both source text and target text. In short, source text and target text which are two different cultural products should be able to construct the same context. Discourse analysis is the means of accomplishing that.

Translators, as any other language users who actively participate in the process of creating meaning, need to be very aware of and conscious about every discursive strategy or choice, ranging from deletion and addition to syntactic and lexical variations, they might adopt during 
the process of producing the target text on the basis of the source text (Mahdiyan, Rahbar, Hosseini-Maasoum, 2013: 46). Here, there are important decisions of translator to create the target text. Before anything else, text genre plays a part in translation act. Secondly, it is a matter of the text function. As a part of both spoken and written discourses the translation act is arranged in correlation with translated text's functional aim.

As mentioned, discourse analysis has, to a great extent, contributed to the notion of translation. Many scholars have made use of D.A in their studies and researches. Researchers, who have looked at translation from discourse analysis point of view, believe discourse as a socio-cultural environment in which communication is taken place (Farahani, 2013: 115). The relevant point of view could be regarded as appropriate because the underlying features of discourses are affected by socio-culture.

Discourse Analysis lays a bridge between source and target text. It defines not only the structure of discourses also tries to explain the social structures which have a role in the construction of source and target text. These social structures configure the discourses, these discourses form a text, this text belongs to a certain function in its belonging community, the translated text is written regarding this function. Discourse analysis in that regard is suggested as a translation strategy. Discourse analysis, as mentioned above, can help the translator during the translation process. Translation has a rich discourse as a result of its interdisciplinarity, and discourse analysis is a requirement in that process. Using discourse analysis translator can develop a critical view and construct target language discourses.

\section{The place of Discourse Analysis in Translator training}

Halliday considers language use as a communicative event and describes three strands of functional meaning as ideational, interpersonal and textual meaning. Interpersonal meaning refers to use of language in order to establish a relationship between text producer and text receiver. Power is one of the rudimentary types of relationship in the analysis of interpersonal meaning. The schemes of choices made by translator from the array of the lexico-grammatical resources of language can establish the interpersonal meaning. Then notions like context, functions, culture, textuality, style, genre, and discourse which are studied in pragmatics, discourse analysis, cultural studies, and communication studies had an effect on Translation practices (Mahdiyan, Rahbar, Hosseini-Maasoum, 2013: 38). The mentioned phenomenons which affect the translation practices should be considered for translator training in which the students make a translation as translator trainees. Whether there are factors which affect the meaning of our discourses, there are also many factors which affect the meaning of discourses both in spoken and written language that students encounter in the translation act. In order to find out the meaning of discourses several ways could be used. In the following, Halliday reflects these ways from his own viewpoint.

"The analysis is carried out within the three functions or meanings of Hallidayan model of language which are; ideational meaning, interpersonal meaning and textual meaning" (Mahdiyan, Rahbar, Hosseini-Maasoum, 2013: 41).

This model shows that the utterances form the ground of analysis. According to ideological, personal and textual features the language is used as a part of the analysis. What affects the language, affects the discourse as well. Thus, coming from the constitution of language, discourses, too, are an element for translation practices.

Translation practices in translator training include usually four main phases; reading, understanding, interpretation and writing. Firstly, paragraphs are divided into sentences and sentences are analyzed. Then, in the context of source text a target text is written. In this phase, translator uses a certain translation strategy. Students as translator prefer the most appropriate strategy. With instructor's direction, a communication is ensured between source 
and target text taking into consideration the discourses of source and target culture. Hence, the ability of foreign language is insufficient for translation act. Beside this, students need translation competence. Due to this advanced translation competence; there are various factors that students must pay attention in the translation process. One of those factors could be discourse analysis. In turn, it should be answered: what discourse analysis through translation contributes to the translator training.

In reading phase, the student begins to analyze the discourses of source text and read the source text in consequence of this analysis. The fact that student analyses the source text's discourses belonging to source culture provides benefit for the student to understand the content and context of source text. Thereby, the understanding phase occurs. One of the factors which have an impact on the understanding phase is student's background knowledge. This knowledge covers professional field about the language and text genre.

Gee (2010: 116) states "a discourse analysis is based on the details of speech (and gaze and gesture and action) or writing that are arguably deemed relevant in the context and that are relevant to the arguments the analysis is attempting to make." (Fahim, Paziraie, 2012: 140). According to Gee, students need an observation in order to analyze disicourses which take place the context of spoken and written text. In a speech this observation is the examination of gaze, gesture and action. In writing this is the reviewing of cultural and textual features. In interpretation phase, the factors based on students (translators) and texts are at stake. In order to interpret a text, students think by taking into account their linguistic competence, foreign language knowledge, professional field and discourse ground (which takes form with student's sense and lifestyle). Besides this, text, text author, text genre, text sender and receiver are prominent. The interpretation phase is the growing point of the other phases. Hence, the mentioned factors in interpretation phase must be considered.

The interpretation changes one from another. Similarly, in a translation act, students translate their texts in different ways. These translated texts have a subjective qualification. Hardly, discourse analysis can be a solution to catch the objectivity among this subjectivity. In discourse analysis both the translator's cognitive and experiential intelligence and source text and culture are at play. Particularly, the examination of these factors through discourse analysis provides that students could improve critical and analytical consideration.

An example for Discourse Analysis in Translator training:

Sanford and Garrod (1981:5), as discourse analysts, demonstrate conclusively the essential role of scenarios in correctly understanding a text:

the message conveyed goes far beyond the individual sentences which make up a text ...

(1) Jill came bouncing down the stairs.

(1') Harry rushed off to get the doctor.

Most readers would interpret this in terms of Jill falling on the stairs injuring herself, and as a result of this Harry calling a doctor. Notice how different the interpretation is when (1) is followed by a slightly different sentence.

(1) Jill came bouncing down the stairs.

(1") Harry rushed over to kiss her.

What this suggests is that far from being tied to the literal content of the component sentences, the message in a text is dependent on the reader bringing additional knowledge in an attempt to come up with a coherent interpretation of the passage as a whole (akt. Hoyle, 2008: 9). In translator training the interpretation of such passages should be fulfilled in the context of the whole text. While the manner of this passage involves independently different meanings from the whole text, the same passage in text can have a disparate meaning. For this reason, in the interpretation phase students must analyze the passage with their translation competence in 
the context of the text. Thus and so, we can criticize the discourses in source text and use Discourse Analyzing translation practices.

Discourse Analysis and Translation practices share the assumption that textual features need to be related to the social and ideological contexts of text production and reception. Translators work in particular socio-political contexts and produce texts for specific purposes and specific audiences. Translations, in other words, reveal the impact of discursive, social and ideological constraints, norms and conventions (Ieţcu-Fairclough, 2008: 67-68). Due to the fact that translation practices are not a monotonous transfer of the textual features, Discourse Analysis and all the things which include Discourse Analysis take place in translation practices. Therefore, discourse analysis should be involved in translator training, particularly, the phase in which students have developed their competences and grown in maturity based on not only their common ground with translated texts and receivers but also textual analysis. Fahim and Paziraie support the idea that translators need some tool in order to grow in maturity.

"There is always a text in which translation takes place, a history from which a text emerges and another one into which a text is transposed. Thus, the common episode between literary texTP and their translations is the idea that none of them is isolated. Therefore, in order to be able to do a qualified translation, translators need to be equipped with some tool, which enables them to analyze the literary texTP translated before, in order to get enough experience for further translations" (Fahim, Paziraie, $2012: 139$ ).

As Fahim and Paziraie say, the translation act necessitates exchanging the messages from various angles with separate tools. Therefore, DA is an appropriate strategy for a quality translation.

This comparative analysis located within Translation practices from a DA viewpoint can provide a broader analytical angle for translation trainees helping them to recognize texTP in connection with all kinds of textual and extra textual constrains such as ideology, power relations, and cultural and historical backgrounds (Mahdiyan, Rahbar, Hosseini-Maasoum, 2013: 46). DA can help translation trainees figure out the period the text is written based on this they can analyze why the text is written. Discourse analysis is helpful in individual development of the students and in the quality of the texts they are going to translate in professional environment.

Therefore, translators, as any other language users who actively participate in the process of creating meaning, need to be very aware of and conscious about every discursive strategy or choice, ranging from deletion and addition to syntactic and lexical variations, they might adopt during the process of producing the target text on the basis of the source text (Khajeh, Khanmohammad, 2009: 40-41). Such a conscious can help translators overcoming problems they encounter during translation process. The experience and knowledge they will not have difficulties understanding the source text. Translators will be experienced enough to know what is required while constructing the target text.

Thus they would be able to grow professionally in skills, knowledge, disposition, demeanor, and credibility (Olher, 2004: 76).

Attlım University is a good example of application of discourse analysis in translator training. Discourse analysis is an obligatory course coordinated by Asst. Prof. İsmail Erton. The course aims to help students analyze the texts both critically and systematically while taking into consideration the factors of form and content which intermingle to form style. In this course the students experience that translation should not be regarded as a sterile linguistic exercise, but an act of communication which includes a rich variety of discourse. To succeed this, not only structural, semantic, pragmatic, semiotic and stylistic analysis of texTP are studied but also the concept of seven standards of textuality analysis and the speech act theory are 
handled through a variety of texts including literary genres. In short the course helps students use discourse analysis in translation process.

When we examine the curriculum of translator training institutions we notice that private universities in particular have adapted discourse analysis into their curriculum. The concepts of universities differ so they have different strategies. However, the significance of discourse analysis in translator training is not to be underestimated. As in At1lım University, a course of discourse analysis can help students develop their understanding and interpreting skills. Particularly discourse analysis should be used in texts and speeches with complex discourses. It would be better for the students to attend discourse analysis course after having had enough linguistic analysis competence. Because discourse analysis makes use of linguistic elements and students need to have a better understanding of the linguistic theory and its elements.

If we continue to explain translation process within the framework of discourse analysis, after students have interpreted the source text within DA, they begin to write target text in the context of target culture's discourses. Writing phase can be easier than others, as the analytical and critical analysis of source text and culture has been carried out. The thing seeming important in this phase is to write the target text considering target culture's discourses which are conformed with source text's discourses. In short, translation trainees analyze target culture's discourses as in source text and then write according to the target language's norms.

A translated text comes up after an extensive research, analysis and co-ordination between source and target text. Students make an effort to translate a text in translator training. Yet, these efforts are not in vain. By this means, they develop both their world knowledge and translation competence. Each text opens doors to students a different and new life. Principally, they enhance their cultural background information as long as they enable both semantic and pragmatic equivalence between source and target text. The fact of this equivalence comes with the discourse analysis strategy for translator training.

Therefore, the language learner as well as the translation trainee, guided by adequate beliefs about the process, make their choices of resources more appropriately, leading to more successful results (Olher, 2004: 74). In addition, students can diagnose discourse related problems in translation and interpreting and find problems to such questions. They can find the connections between discourses and they can identify their point of origin and supportive elements.

By applying this model of DA, the instructors and students can analyze the translated texts accurately and understand how much their translations are coherent. Moreover, the instructors and students can analyze the books translated before by different translators, to find out which one is more cohesive (Fahim, Paziraie, 2012: 145). The analysis of translated texts by students and their competence in deciding on the correct translation indicate their competence in translation. Moreover, if students can analyze the vocabulary of the translated texts and speeches scientifically, that is an indication of the contribution of DA to translator training.

A discourse-oriented approach can encourage as well learners to develop language awareness, exploring relationships between form, meaning and use. From a cognitive perspective, Grabe (2009) argues for building awareness of discourse through several techniques, mainly through highlighting key words that signal text structure, identifying a paragraph's function, and finding patterns of discourse organization in a text. Finally, a discourse-oriented approach can allow instructors to evaluate interactions within the classroom (McCarthy, Matthiessen \& Slade, 2002) in order to enhance understanding (Alqahtani, Aljidy, 2011: 1512). The focus here is on the words' function as an indicator of a text's discourse. A discourse analysis as such, might contribute to finding the phrases that determines text structure and meaning, it 
will help instructors' to comprehend the discourse differences in the class and better understand students as well.

In spite of the contributions of DA or DA into Translation Practices, Discourse Analysis appears partially or never in Translator Training. Discourse Analysis is a strategy for Translation Practice; in addition it should be a lesson in Translator Training which helps students along the translation process. Especially, at the first period students can take discourse analysis strategy in linguistic and then, at the second period they can have Discourse Analysis and Translation Act Course. Thus, they can learn both the source points of discourse analysis and acquire a translation competence within Discourse Analysis. DA can be supportive in translator training to help students apply what they have learned and have a critical and analytical thinking towards translation.

\section{Conclusion}

Discourse research is not narrow comprehensive language analysis that is only based on the sentence about the sayings. They can be regarded as a qualitative research method which presents a wide comprehensive point of view to social sciences and provides a high-level commentary possibility on how meaning construction occurs, being based on all these, and emphasizes that how it structures the language on social environment, language users.

This method leads translator and translation trainee to solve the language of the text. Solving implicit meanings, connotations, plain meaning etc. occurring on the language of source text occurs with according to concept and again finding the retaliation of these utterances of these words in ideal language, producing them according to ideal cultural norms actualize with the translator of discourse analysis research. For instance, a translation trainee dealing with only the plain meaning of the text words causes the meaning loss while composing the ideal text and the translation text doesn't respond to the needs of goal mass in this way translation text wouldn't be a successful text. At this point, discourse analysis method which will contribute to translation trainee in positive way can be applied. If translator continues the translation process with this method;

$>$ Analyzing the sub-structure of social discourse and determining the retaliation of these at the goal language

$>$ Developing the process of reading comprehension

$>$ Uniting the reading comprehension activity with the kind of text

$>$ Determining the text elements

$>$ Recognizing the text and its' references

$>$ Preparing the background to contribute to text elements (adjustment of the data to ideal test got by the analysis of discourse facts in culture)

$>$ The ability of observing the problems in advance at the process of producing the goal text by identifying the places of linguistic parameters encountered in both oral and written text can be obtained.

From the viewpoint of this study is deduced that DA can only one of the strategies, which are used to facilitate the process of translation training and Discourse Analy'sis and Translation Training have a reciprocal communication system. 


\section{REFERENCES}

- Alqahtani, A. A., \& Aljidy, A. B. (2011). Reading TexTP in Translation Classes: Discourse Analysis Perspectives. Theory and Practice in Language Studies,1(11), 1507-1513

- Erton, I. (2014). Discourse Analysis in Translator training at the University Level: an Assessment of StudenTP' Attitudes. HACETTEPE UNIVERSITESI EGITIM FAKULTESI DERGISI-HACETTEPE UNIVERSITY JOURNAL OF EDUCATION, 29(1), 114-125

- Fahim, M., \& Paziraie, M. E. (2012). Transmission of Postcolonialism through Translation, Discourse Analysis of" Heart of Darkness" and Two of iTP Persian Translations at Micro and Macro Levels. Journal of American Science, 8(1). 139-146.

- Farahani, M. V. (2013). The Role of Discourse Analysis in Translation.International Journal of Applied Linguistics \& English Literature, 2(1).112-116.

- Hoyle, R. A. (2008). Scenarios, discourse, and translation: The scenario theory of cognitive linguistics, iTP relevance for analysing New Testament Greek and modern Parkari texTP, and iTP implications for translation theory. SIL International: SIL eBooks.-2008.-Режим доступу до джерела: http://www. sil. org/silepubs/abstract. asp.

- Ietcu-Fairclough, I. (2008). Discourse Analysisand translation practices: translation, recontextualization, ideology. Bucharest Working Papers in Linguistics, (2), 67-72.

- Jørgensen, M. W., \& Phillips, L. J. (2002). Discourse analysis as theory and method. Sage.

- Khajeh, Z., \& Khanmohammad, H. (2009). Transmission of ideology through translation: A Discourse Analysisof Chomsky's "Media Controll" and iTP persian translations. Iranian journal of applied language studies, 1(1), 24-42.

- Mahdiyan, M., Rahbar, M., \& Hosseini-Maasoum, S. M. (2013). Applying Discourse Analysisin Translation of Political Speeches and Interviews.Academic Journal of Interdisciplinary Studies, 2(1), 35-47.

- Olher, R. M. (2004). Translation \& Discourse-DOI: 10.4025/actascihumansoc. v26i1. 1560. Acta Scientiarum. Human and Social Sciences, 26(1), 73-79.

- Oxford Idioms Dictionary-for learners of English (2001), Oxford University Press.

- Sayfuldeen, A.S.A.M. (2010). Discourse Analysis for Translation with Special Reference to the Consecutive Interpreter's Training, Journal of the College of ArTP. University of Basrah,(51), 25-40.

- Y Álvaro, L. M. R. C., \& Fujihara, K. TEXTUAL GENRES ON DISCOURSE ANALYSIS AND TRANSLATION FUNCTIONALISM 